\title{
Recession, recovery and suicide in mental health patients in England: time trend analysis
}

\author{
Saied Ibrahim, Isabelle M. Hunt, Mohammad S. Rahman, Jenny Shaw, Louis Appleby and Nav Kapur
}

\section{Background}

The 2008 economic recession was associated with an increase in suicide internationally. Studies have focused on the impact in the general population with little consideration of the effect on people with a mental illness.

\section{Aims}

To investigate suicide trends related to the recession in mental health patients in England.

\section{Method}

Using regression models, we studied suicide trends in mental health patients in England before, during and after the recession and examined the demographic and clinical characteristics of the patients. We used data from the National Confidential Inquiry into Suicide and Safety in Mental Health, a national data-set of all suicide deaths in the UK that includes detailed clinical information on those seen by services in the last 12 months before death.

\section{Results}

Between 2000 and 2016, there were 21224 suicide deaths by patients aged 16 or over. For male patients, following a steady fall of $0.5 \%$ per quarter before the recession (quarterly percent change (QPC) 2000-2009-0.46\%, 95\% Cl -0.66 to -0.27), suicide rates showed an upward trend during the recession (QPC 2009$20112.37 \%, 95 \% \mathrm{Cl}-0.22$ to 5.04). Recession-related rises in suicide were found in men aged $45-54$ years, those who were unemployed or had a diagnosis of substance dependence/misuse. Between 2012 and 2016 there was a decrease in suicide in male patients despite an increasing number of patients treated. No significant recession-related trends were found in women.

\section{Conclusions}

Recession-associated increases in suicide were seen in male mental health patients as well as the male general population, with those in mid-life at particular risk. Support and targeted interventions for patients with financial difficulties may help reduce the risk at times of economic hardship. Factors such as drug and alcohol misuse also need to be considered. Recent decreases in suicide may be related to an improved economic context or better mental healthcare.

\section{Declaration of interest}

N.K. is supported by Greater Manchester Mental Health NHS Foundation Trust. L.A. chairs the National Suicide Prevention Strategy Advisory Group at the Department of Health (of which N.K. is also a member) and is a non-executive Director for the Care Quality Commission. N.K. chairs the National Institute for Health and Care Excellence (NICE) depression in adults guideline and was a topic expert member for the NICE suicide prevention guideline.

\section{Keywords}

Suicide; recession; mental health patients; mental illness; economic crisis.

\section{Copyright and usage}

(c) The Royal College of Psychiatrists 2019.
Following a relatively steady 16 -year period of economic growth, the UK experienced a major economic downturn in 2008 leading to the worst recession seen in 60 years. ${ }^{1}$ This led to negative changes in income, education, health, and the housing and labour market. ${ }^{2,3}$ Several studies have investigated the link between economic conditions and suicide. A number of factors might act at an individual and societal level such as increasing debt, home repossession, job insecurity and unemployment. There is international evidence of a significant association between rapid short-term economic downturn and suicide deaths, with men particularly affected and the effects in women being smaller or none. ${ }^{4-8}$ As one of the most vulnerable groups in society, some have suggested that the effect of economic recession might be even more marked in those who are mentally ill or those already at high risk of suicide. ${ }^{9,10}$ Previous research has shown increasing trends in mental health problems and widening inequalities in unemployment and wages after the onset of recession. ${ }^{11}$ Furthermore, the increase in suicide risk post-recession has been found to be greater among those with low levels of education, who are likely to be more vulnerable to job loss, with increasing debt and challenges in finding employment in a competitive labour market. ${ }^{12}$ Currently, the UK appears to be recovering from this global crisis although the outlook remains uncertain. ${ }^{13}$

Suicide trends in mental health patients in relation to the recession have not previously been explored. They may or may not be the same as the recession-related trends in the general population. Suicide in mental health patients may involve different aetiological factors and processes from those operating in the general population. On the one hand some people receiving mental healthcare may be protected by being out of the labour market. On the other hand, they may be more vulnerable, particularly if care received is compromised by mental health services that are under increased resource pressure during a recession. A recent study suggested that economic hardship may intensify the social exclusion experienced by people with mental health problems. ${ }^{14}$ In addition, individual-level sociodemographic and clinical information on those who have died by suicide before, during the recession and in the recent periods of economic recovery are limited, especially on a national level. ${ }^{15}$ In this study we investigated recession-related trends in suicide in patients with a recent history of mental health service contact using a comprehensive national sample. Our specific objectives were to examine trends in suicide before and after the onset of the recession as well as the recent economic recovery period, and to describe the sociodemographic and clinical characteristics of those who were most affected at this time. We examined the effects for men and women separately given the established gender differences in suicidal behaviour. ${ }^{16}$

\section{Method}

\section{Data collection}

Suicide data were collected as part of the National Confidential Inquiry into Suicide and Safety in Mental Health (NCISH). 
NCISH collects in-depth, individual-level clinical information about those who died by suicide who have been in recent $(<12$ months) contact with mental health services. In summary, data collection occurred in three stages. First, information on all deaths in England that received a conlclusion of suicide or an undetermined (open) conclusion at coroner's inquest was obtained from the Office for National Statistics (ONS). Undetermined conclusions were included as most are thought to be cases of suicide and are conventionally used in suicide rate estimation in the UK. Second, information on whether the deceased had been in contact with mental health services in the 12 months before death was obtained from the hospitals and community services providing mental healthcare in the deceased's district of residence and from the adjacent districts. Third, demographic and clinical data on those who had been in contact with services (referred to as 'patients') were obtained by sending a questionnaire to the responsible consultant psychiatrist. The questionnaire included sections covering sociodemographics, psychosocial history, method of suicide and aspects of care received prior to death. Some of the demographic and factual information (for example method of death) is also received from the ONS. Further detailed information on the data-collection process is available elsewhere. ${ }^{17}$

Quarterly suicide data were analysed between 2000 and 2016 and we investigated suicide rates in the adult age population (16 years or over). Suicide rates were determined using general population estimates in England as denominator data. ${ }^{18}$ Because of the time taken for patient data to be collected and processed, we had a questionnaire completeness rate of $80 \%$ in 2016. To avoid underestimation of suicide deaths, we used the suicide rate in the $80 \%$ of completed questionnaires to estimate the additional number of suicides expected had $100 \%$ of questionnaires been completed and returned. We began our analysis with time trend models investigating linear trends using joinpoint regression analysis, which can be used to describe changes in trend data. ${ }^{19}$ We estimated and identified points (i.e. 'joinpoints') where there were significant changes in temporal trends in suicide in both the patient and general population between 2000 and 2016. Although we were interested in the effects of the recession, rather than using fixed time points, joinpoint analysis enabled us to identify precisely where changes in trends occurred. This also allowed us to detect any lead or lag effects of the recession that may have been operating in relation to suicide rates. Previous work has suggested that the timing of recession-related changes in suicide may vary according to gender and age group. ${ }^{10}$ Next, we compared the sociodemographic and clinical characteristics of patients who died by suicide during three time periods: 2004-2008, 2009-2011 and 2012-2016. These years were based on the joinpoint analysis and in line with changes in gross domestic product (GDP) and the UK labour market indicating when the recession occurred; we have referred to these as 'pre-recession' (2004-2008), 'recession' (2009-2011), and 'recovery' (2012-2016) periods. ${ }^{20} \mathrm{We}$ examined gender-specific patient suicide deaths by age, employment status, marital status, primary psychiatric diagnosis, method of suicide and whether the person was an in-patient or a community patient at the time of death.

\section{Statistical analysis}

For the joinpoint analysis, we fitted regression models with suicide rates (calculated using general population estimates as denominators) as the dependent variable and the time period as the main independent variable. We used the grid-search method with uncorrelated errors and the permutation test to determine the best joinpoint models and we estimated the quarterly percent change (QPC) in suicide rates (with 95\% CI) from the line segments between the 'points' identified. For patient suicide deaths, the analysis was also performed separately for age groups of 16-24, $25-34,35-44,45-54,55-64$ and $\geq 65$ for men and women. For the analysis on the three time periods pre- and post-recession, we fitted gender-specific multinomial logistic regression models. We compared the characteristics of individuals who died in each time period by calculating the odds of patients having particular clinical and demographic characteristics. We were interested in sequential changes and so compared each time period to the one preceding it. Thus, we compared patient characteristics in the recession period (2009-2011) to the pre-recession period (2004-2008), and patient characteristics in the post-recession period (2012-2016) to the recession period. Trend analysis was carried out using the Joinpoint Regression Program (Version 4.4.0.0 January 2017) from Statistical Research and Applications Branch, National Cancer Institute. ${ }^{19}$ All other analyses were undertaken using Stata 13.1 software. $^{21}$

\section{Ethical approval}

NCISH received approval from the National Research Ethics Service Committee North West (Greater Manchester South, UK). Informed consent was not obtained as the participants were deceased. Exemption under Section 251 of the NHS Act 2006, enabling access to confidential and identifiable information without informed consent in the interest of improving care, was therefore also obtained from the Health Research Authority Confidentiality Advisory Group.

\section{Results}

During 2000 to 2016, there were 77184 suicide deaths in people aged 16 or over in England in the general population, a rate of 10.8 per 100000 population. Male suicides rates were higher at 16.8 per 100000 population and female suicide rates lower at 5.2 per 100000 population. Of all the general population deaths, 21 $224(27 \%)$ were by people in contact with mental health services in the last 12 months. Two-thirds of patient suicides were among male patients $(14026,66 \%)$.

\section{Time trends: joinpoint analysis by gender and age group}

Figure 1 shows total and gender-specific patient suicide rates between 2000 and 2016 by quarter. For information we have also included trends in GDP, a measure of economic performance. The line segments measuring the QPC from the best joinpoint models for all suicide deaths and for men and women are also shown in Fig. 1. We identified two joinpoints for male patients and for female patients as the best models in the joinpoint analysis.

We found there was a steady decline in male patient suicide rates of $0.5 \%$ per quarter from the beginning of 2000 to the last quarter of 2009 (QPC $=-0.46,95 \%$ CI -0.66 to $-0.27, P<0.001$ ) (Table 1). This was followed by a rise of $2.4 \%$ from the last quarter of 2009 till the end of 2011, (QPC $=2.37 \%, 95 \%$ CI -0.22 to $5.04, P=0.07)$. Recent years from the last quarter of 2011 to the last quarter of 2016 showed a fall of $1.3 \%$ per quarter $(95 \% \mathrm{CI}-1.83$ to $-0.80, P<0.001)$. These trends were similar to those found in the general population. In female patients we found a non-significant fall between the third quarter of 2005 and the third quarter of 2006 $(\mathrm{QPC}=-5.69 \%, 95 \% \mathrm{CI}-17.9$ to $8.28, P=0.4)$ but no significant trends over the study period (Table 1).

Patient suicide deaths in men aged 16-24 showed a fall between quarter 1 of 2000 to quarter 3 of 2007 (QPC $=-1.73,95 \% \mathrm{CI}-2.79$ to $-0.66, P=0.002$ ), after which they increased until the end of 2016 , although the rise failed to meet the threshold of statistical significance at the $5 \%$ level $(\mathrm{QPC}=0.68,95 \% \mathrm{CI}-0.12$ to $1.48, P=0.09$ ) (Table 2$)$. 


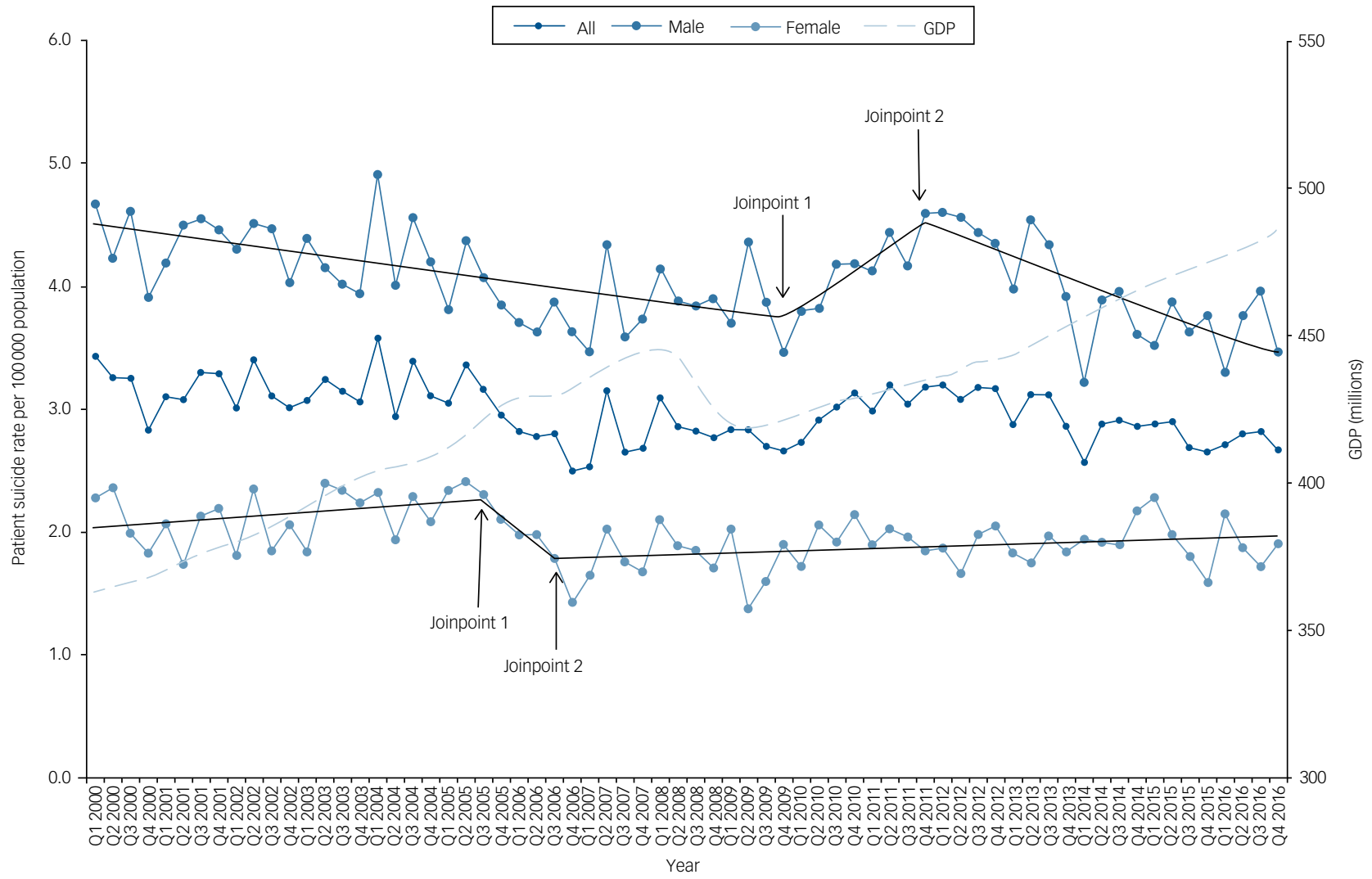

Fig. 1 Patient suicide rates and UK gross domestic product (GDP - low level aggregates) per quarter between 2000 and 2016.

Gender-specific trend lines for suicide rates and where changes in trends (joinpoints) occurred are shown. Q1, Q2, Q3, Q4, quarters 1, 2, 3, 4, respectively.

In men aged $45-54$, suicide rates were stable between the beginning of 2000 to the last quarter of 2007 but this was then followed by an increase that lasted until the second quarter of $2012(\mathrm{QPC}=1.84$,

\begin{tabular}{|c|c|}
\hline $\begin{array}{l}\text { Population, all ages } \geq 16 \text { years by } \\
\text { gender, trends (by quarter) }\end{array}$ & $\mathrm{QPC}(95 \% \mathrm{Cl}), P$ \\
\hline \multicolumn{2}{|l|}{$\begin{array}{l}\text { Patients, males } \\
2 \text { joinpoints }\end{array}$} \\
\hline Q1 2000-Q4 2009 & $-0.46(-0.66$ to -0.27$),<0.001$ \\
\hline Q4 2009-Q4 2011 & 2.37 (-0.22 to 5.04), 0.07 \\
\hline Q4 2011-Q4 2016 & $-1.31(-1.83$ to -0.80$),<0.001$ \\
\hline \multicolumn{2}{|l|}{$\begin{array}{l}\text { Patients, females } \\
2 \text { joinpoints }\end{array}$} \\
\hline Q1 2000-Q3 2005 & $0.50(-0.14$ to 1.15$), 0.12$ \\
\hline Q3 2005-Q3 2006 & $-5.69(-17.9$ to 8.28$), 0.40$ \\
\hline Q3 2006-Q4 2016 & $0.23(-0.04$ to 0.49$), 0.09$ \\
\hline \multicolumn{2}{|l|}{$\begin{array}{l}\text { General population, males } \\
2 \text { joinpoints }\end{array}$} \\
\hline Q1 2000-Q3 2010 & $-0.41(-0.52$ to -0.29$),<0.001$ \\
\hline Q3 2010-Q1 2012 & 1.94 (-0.94 to 4.91$), 0.19$ \\
\hline Q1 2012-Q4 2016 & $-0.67(-1.04$ to -0.31$), 0.001$ \\
\hline \multicolumn{2}{|l|}{$\begin{array}{l}\text { General population, females } \\
2 \text { joinpoints }\end{array}$} \\
\hline Q1 2000-Q2 2005 & $-0.17(-0.82$ to 0.25$), 0.42$ \\
\hline Q2 2005-Q1 2006 & $-5.35(-20.4$ to 12.5$), 0.53$ \\
\hline Q1 2006-Q4 2016 & $0.03(-0.12$ to 0.19$), 0.69$ \\
\hline
\end{tabular}

95\% CI $0.42-3.29, P=0.01$ ), after which rates fell until the end of 2016. Trends in the older age groups showed a steady rise in the 55 - to 64-year-olds and no changes in those aged $\geq 65$.

Table 2 Joinpoint regression models on trends in male patient suicide deaths between 2000 and 2016 in England by age groups ${ }^{a}$

Male patients, by age group, trends

(by quarters)

QPC $(95 \% \mathrm{Cl}), P$

Age group, 16-24 years

1 joinpoint

Q1 2000-Q3 2007

Q3 2007-Q4 2016

$-1.73(-2.79$ to -0.66$), 0.002$ $0.68(-0.12$ to 1.48$), 0.09$

Age group, 25-34 years

0 joinpoints

Q1 2000-Q4 2016

$-0.94(-1.13$ to -0.75$),<0.001$

Age group, 35-44 years

0 joinpoints

Q1 2000-Q4 2016

$-0.19(-0.38$ to 0.01$), 0.063$

Age group, 45-54 years

2 joinpoints

Q1 2000-Q4 2007

Q4 2007-Q2 2012

Q2 2012-Q4 2016

$-0.29(-0.92$ to 0.35$), 0.37$

1.84 (0.42 to 3.29$), 0.012$

$-2.06(-3.33$ to -0.84$), 0.001$

Age group, 55-64 years

0 joinpoints

Q1 2000-Q4 2016

$0.52(0.30$ to 0.74$),<0.001$

Age group, $\geq 65$ years

0 joinpoints

Q1 2000-Q4 2016

$0.19(-0.07$ to 0.44$), 0.15$

QPC, quarterly percent change between the changes in trends (joinpoints); Q1, Q2, Q3, Q4, quarters 1, 2, 3, 4, respectively.

Q4, quarters $1,2,3,4$, respectively.
a. Figures in bold indicate statistically significant results. 
Patient suicide deaths in women showed no noticeable age-specific trends with the exception of falls in the 25- to 34-year-olds over the study period $(\mathrm{QPC}=-0.59,95 \% \mathrm{CI}-0.91$ to $-0.26, P=0.001)$ and falls from the first quarter of 2005 to the end of the study period in women aged $55-64(\mathrm{QPC}=-0.54,95 \% \mathrm{CI}-1.03$ to $-0.05, P=0.03)$.

\section{Patient characteristics before, during and after the onset of the recession: comparing three time periods}

There were significant differences in the three time periods with respect to characteristics of the patients who had died by suicide (see Tables 3 and 4 and also supplementary Tables 1 and 2 that include more detailed information for each time period, available at https://doi.org/10.1192/bjp.2019.119). Men who died in the recession period (2009-2011) were more likely to be aged 45-54 compared with those who died in the pre-recession period (2004-2008). Women who died during the recession were more likely to be single compared with those who died pre-recession. In both genders, those who died during the recession were more likely to be unemployed and have had a diagnosis of drug dependence/misuse than those who died pre-recession. Conversely, those who died during the recession were less likely to be on long-term sickness benefit and be an inpatient than those who died during the pre-recession period.

In comparison with the recession period (2009-2011), the postrecession period (2012-2016) showed men who died were more likely to be aged $16-24$, aged $\geq 65$, retired and have died by hanging. They were less likely to be aged 35-44, on long-term sickness benefit, be an in-patient or to have died by self-poisoning. Women who died in the post-recession period were more likely to be single at the time of death, have a primary diagnosis of personality disorder and die by hanging compared with those who died in the recession period. They were less likely to have had a diagnosis of alcohol dependence or to have died by drowning.

\section{Discussion}

Our joinpoint analysis showed that there was a rise in the number of patient suicide deaths in men during the period of economic recession, with an upward trend from 2009-2011 similar in magnitude to the male general population during the same time period. This upward trend was particularly evident in men in midlife (aged 45-54 years). In younger men (aged 16-24 years) the historical fall in rates ended and there was a slight upward trend post-2007 that did not reach the level of statistical significance. We did not observe any recession-related trends in suicide rates among women during the study period.

In relation to changes in patient characteristics, those who died by suicide in the recession were more likely to be unemployed than those who died before the recession but less likely to be on longterm sickness. Changes in the diagnostic profile of patients who had died were evident for both men and women, with a rise in those with drug dependence/misuse during the recession.

Suicide deaths among male patients fell in the post-recession period (2012-2016) with the fall most evident among those aged 45-54 years. The recent period showed an increase in patient suicide deaths by hanging with corresponding falls in patient suicide deaths by self-poisoning in men and drowning in women compared with previous years.

\section{Findings in the context of previous research}

Consistent with previous studies, we found an adverse effect of the economic recession in male suicide deaths in the general population, ${ }^{4-5,8}$ but an increase in patient suicide was also evident in our study. In women, studies have shown the incidence of suicide has been largely unchanged post-recession although reports have indicated a rise in self-harm rates. ${ }^{22}$ Similar to other studies, we found no recession-related trends in suicide rates in women, both in mental health patients and in the general population. ${ }^{4,5,8}$

A previous study found a halt in downward trends in suicide rates in England and Wales in 2006 among the 16- to 24-yearolds and a rise among the 35 - to 44 -year-olds. ${ }^{10}$ In our study we found a similar halt in patient suicide rates among those aged 16-24 from the third quarter of 2007 to the end of the study period, but there were no changes in suicide trends in those aged 35-44. A rise in suicide deaths in middle-aged men after the onset

Table 3 Comparison of the sociodemographic characteristics of patients who died by suicide in England in pre-recession (2004-2008), recession (20092011) and economic 'recovery' (2012-2016) periods (a more detailed table including all data for the three periods is available as supplementary Table 1)

\begin{tabular}{|c|c|c|c|c|c|c|}
\hline \multirow[b]{3}{*}{ Characteristics } & \multicolumn{3}{|c|}{ Men, $n=10446(66 \%)$} & \multicolumn{3}{|c|}{ Women, $n=5330(34 \%)$} \\
\hline & \multicolumn{2}{|c|}{ Odds ratio $(95 \% \mathrm{Cl})$} & \multirow[b]{2}{*}{$\begin{array}{l}\text { Statistics, } \\
\chi^{2} \text { (d.f.), } P\end{array}$} & \multicolumn{2}{|c|}{ Odds ratio $(95 \% \mathrm{Cl})$} & \multirow[b]{2}{*}{$\begin{array}{l}\text { Statistics, } \\
\chi^{2} \text { (d.f.), } P\end{array}$} \\
\hline & $\begin{array}{l}2009-2011 \text { v. } \\
2004-2008^{b}\end{array}$ & $\begin{array}{c}2012-2016 \text { V. } \\
2008-2011^{c}\end{array}$ & & $\begin{array}{c}2009-2011 \mathrm{v} . \\
2004-2008^{b}\end{array}$ & $\begin{array}{c}2012-2016 \text { V. } \\
2009-2011^{c}\end{array}$ & \\
\hline Age groups, years & & & $85.6(10),<0.001$ & & & 19.9 (10), 0.03 \\
\hline $16-24$ & $0.95(0.77-1.16)$ & $1.22(1.00-1.48)$ & & $1.25(0.94-1.66)$ & $1.18(0.90-1.54)$ & \\
\hline $25-34$ & $0.85(0.74-0.97)$ & $0.95(0.83-1.09)$ & & $0.89(0.73-1.09)$ & $0.98(0.79-1.20)$ & \\
\hline $35-44$ & $0.92(0.82-1.03)$ & $0.80(0.71-0.90)$ & & $0.93(0.78-1.11)$ & $0.96(0.81-1.15)$ & \\
\hline $45-54$ & $1.26(1.12-1.41)$ & $1.04(0.93-1.17)$ & & $1.07(0.91-1.26)$ & $1.06(0.90-1.25)$ & \\
\hline $55-64$ & $1.06(0.92-1.21)$ & $0.93(0.81-1.07)$ & & $1.00(0.83-1.20)$ & $0.85(0.71-1.03)$ & \\
\hline$\geq 65$ & $0.96(0.82-1.12)$ & $1.37(1.18-1.60)$ & & $0.99(0.82-1.20)$ & $1.06(0.87-1.28)$ & \\
\hline Civil status & & & $9.48(6), 0.15$ & & & $42.2(6),<0.001$ \\
\hline Divorced/separated & $0.95(0.85-1.06)$ & $0.91(0.81-1.03)$ & & $0.93(0.79-1.10)$ & $0.93(0.79-1.10)$ & \\
\hline Married/cohabiting & $1.03(0.92-1.15)$ & $0.98(0.88-1.10)$ & & 0.89 (0.76-1.03) & $0.95(0.81-1.11)$ & \\
\hline Single & $1.03(0.92-1.13)$ & $1.09(0.99-1.21)$ & & $1.27(1.09-1.48)$ & $1.21(1.04-1.41)$ & \\
\hline Widowed & $0.99(0.77-1.27)$ & $0.97(0.75-1.25)$ & & $0.91(0.72-1.15)$ & $0.80(0.62-1.02)$ & \\
\hline Employment status & & & $152.2(10),<0.001$ & & & $63.7(10),<0.001$ \\
\hline In paid employment & $1.03(0.91-1.17)$ & $1.02(0.90-1.15)$ & & 1.09 (0.90-1.32) & $0.99(0.82-1.20)$ & \\
\hline Unemployed & $1.15(1.04-1.27)$ & $0.94(0.85-1.04)$ & & $1.26(1.08-1.46)$ & $1.13(0.97-1.31)$ & \\
\hline Full-time student & $1.62(1.01-2.60)$ & 1.07 (0.70-1.64) & & $1.11(0.66-1.87)$ & $1.37(0.84-2.24)$ & \\
\hline Long-term sick & $0.72(0.62-0.83)$ & $0.72(0.61-0.84)$ & & $0.78(0.63-0.95)$ & $0.89(0.72-1.10)$ & \\
\hline Retired & $0.95(0.82-1.10)$ & $1.27(1.10-1.47)$ & & 1.07 (0.89-1.29) & $0.92(0.76-1.12)$ & \\
\hline Other status & $1.57(0.83-2.96)$ & $2.85(1.72-4.70)$ & & $0.67(0.54-0.84)$ & $0.90(0.70-1.14)$ & \\
\hline
\end{tabular}


Table 4 Comparison of clinical characteristics of patients who died by suicide in England in pre-recession (2004-2008), recession (2009-2011) and economic 'recovery' (2012-2016) periods (a more detailed table including all data for the three periods is available as supplementary Table 2)

\begin{tabular}{|c|c|c|c|c|c|c|}
\hline \multirow[b]{3}{*}{ Clinical characteristics } & \multicolumn{3}{|c|}{ Men, $n=10446(66 \%)$} & \multicolumn{3}{|c|}{ Women, $n=5330$ (34\%) } \\
\hline & \multicolumn{2}{|c|}{ Odds ratio $(95 \% \mathrm{Cl})$} & \multirow[b]{2}{*}{$\begin{array}{l}\text { Statistics, } \chi^{2} \\
\text { (d.f.), } P\end{array}$} & \multicolumn{2}{|c|}{ Odds ratio $(95 \% \mathrm{Cl})$} & \multirow[b]{2}{*}{$\begin{array}{l}\text { Statistics, } \chi^{2} \\
\text { (d.f.), } P\end{array}$} \\
\hline & $\begin{array}{l}2009-2011 v . \\
2004-2008^{b}\end{array}$ & $\begin{array}{l}2012-2016 V . \\
2008-2011^{c}\end{array}$ & & $\begin{array}{l}2009-2011 v . \\
2004-2008^{b}\end{array}$ & $\begin{array}{l}2012-2016 \mathrm{~V} . \\
2009-2011^{c}\end{array}$ & \\
\hline In- or out-patient at time of death & & & $77.6(2),<0.001$ & & & $24.9(2),<0.001$ \\
\hline In-patient & $0.64(0.54-0.77)$ & $0.76(0.62-0.93)$ & & $0.71(0.56-0.91)$ & $0.83(0.64-1.07)$ & \\
\hline Out-patient & $1.56(1.30-1.87)$ & $1.31(1.07-1.61)$ & & $1.40(1.10-1.78)$ & $1.21(0.93-1.57)$ & \\
\hline Primary diagnosis & & & $17.2(8), 0.001$ & & & 28.9 (8), 0.001 \\
\hline $\begin{array}{l}\text { Schizophrenia and other delusional } \\
\text { disorders }\end{array}$ & $0.90(0.79-1.02)$ & $1.12(0.98-1.27)$ & & $0.97(0.79-1.21)$ & $0.98(0.78-1.22)$ & \\
\hline Affective disorders & $1.03(0.93-1.15)$ & $1.06(0.94-1.18)$ & & $0.91(0.77-1.06)$ & $0.95(0.81-1.12)$ & \\
\hline Alcohol dependence/misuse & $0.96(0.81-1.14)$ & $0.82(0.68-1.00)$ & & $1.03(0.75-1.41)$ & $0.67(0.48-0.95)$ & \\
\hline Drug dependence/misuse & $1.25(1.00-1.57)$ & $0.97(0.77-1.21)$ & & $1.40(0.91-2.18)$ & $0.79(0.51-1.22)$ & \\
\hline Personality disorder & $1.04(0.86-1.27)$ & $0.95(0.77-1.16)$ & & $1.13(0.91-1.39)$ & $1.33(1.09-1.64)$ & \\
\hline Method of suicide ${ }^{d}$ & & & $33.7(6),<0.001$ & & & $33.2(6),<0.001$ \\
\hline Self-poisoning & $1.05(0.93-1.19)$ & $0.77(0.68-0.87)$ & & $1.05(0.90-1.22)$ & $0.85(0.72-0.99)$ & \\
\hline Hanging/strangulation & $1.10(0.99-1.22)$ & $1.13(1.01-1.25)$ & & $1.00(0.85-1.16)$ & $1.39(1.19-1.62)$ & \\
\hline Jumping/multiple injuries & $0.89(0.77-1.02)$ & 1.05 (0.92-1.21) & & $0.93(0.76-1.14)$ & 0.89 (0.72-1.09) & \\
\hline Drowning & $0.70(0.54-0.91)$ & $1.25(0.96-1.63)$ & & $0.99(0.76-1.29)$ & $0.71(0.54-0.95)$ & \\
\hline $\begin{array}{l}\text { a. Figures in bold indicate statistically sign } \\
\text { b. Multinomial logistic regression models: } \\
\text { c. Multinomial logistic regression models: } \\
\text { d. Method of suicide - excluding other me }\end{array}$ & $\begin{array}{l}\text { sults. } \\
\text { nsion as baseline grc } \\
\text { n onset as baseline }\end{array}$ & & & & & \\
\hline
\end{tabular}

of the recession has been reported in other studies. ${ }^{23}$ In line with previous literature, we found no recession-related trends in suicide rates among women.

We found the recession-related rise in patient suicide deaths in middle-aged men has been followed by a fall in the most recent years (2012-2016). Our study also found a fall in in-patient deaths post2008 but this is unlikely to be related to wider economic factors as a continuous fall in in-patient suicide deaths between 2003 and 2011 has previously been shown. ${ }^{24}$

Previous English studies have linked a rise in suicide with increases in unemployment, ${ }^{8}$ while others have found mixed evidence of an association between suicide and unemployment. ${ }^{25} \mathrm{We}$ found an increase in the number of patient suicide deaths after the onset of the recession in those who were unemployed in both men and women. However, this rise coincided with a fall in suicide numbers in those who were long-term sick at the time of death. The upward trend in suicides after the beginning of the recession in young adult males may be explained by the difficulties faced in financing education or finding work for the first time. ${ }^{10}$ In contrast, middle-aged men may be more exposed to the risks associated with financial difficulties through job loss and benefit cuts. Of note, this rise in suicide in unemployed patients alongside a fall in those who were sick longterm could be linked to the introduction of employment and support allowance (ESA) in 2008 - a welfare benefit that replaced incapacity (sickness) benefit, income support and severe disability allowance paid because of a disability or illness. ${ }^{26}$ A welfare reform report found that re-assessments of those on incapacity benefit resulted in around a quarter of previous claimants not being deemed eligible for ESA. ${ }^{26}$ This reduction in the number of people receiving sickness-related benefit may account for the fall in the number of suicide deaths in this group. In addition, our finding of a rise in patient suicide deaths post-recession in men with drug dependence/misuse may be related to the effects of the recession increasing psychological stress resulting in increased drug use. ${ }^{27}$

\section{Strengths and limitations}

To our knowledge, this is the first study to examine recessionrelated trends and characteristics of suicides in a patient population. We were also able to investigate trends in the most recent years to examine the association between suicides and potential economic recovery. Nevertheless, certain limitations need to be highlighted.

First, we examined patient suicides rates using general population estimates as denominators rather than calculating more informed suicide rates from the target population, i.e. people with a mental illness in service contact. We considered using the number of people in contact with secondary mental health services as denominator data from the Mental Health Services Dataset - a routinely collected data-set of service contact. ${ }^{28}$ However, time periods were not comparable because of changes to the methodology of how these routine service data have been collected - first around 2011 and then again in 2014 and 2016 with the inclusion of other patient groups such as those with intellectual disabilities, and collection of data from independent organisations as well as a general improvement in data quality. These data have changed significantly over time with half a million men in service contact in 2005 rising to over $1.1 \mathrm{~m}$ in 2016 . When we explored this further in post hoc analysis (details available on request from the authors) we found that the trends in patient suicide we observed in this study are unlikely to simply be as a result of changing levels of contact with mental health services.

Second, the three different time periods on which we examined patient characteristics were based on our joinpoint findings and on generally accepted pre-recession, recession and post-recession periods determined a priori. To account for any possible variation in recession onset or duration, we performed a sensitivity analysis comparing changes in patient characteristics between 2004-2007 to 2008-2012 and 2013-2016 and found no major differences in our results shown in Tables 3 and 4 and supplementary Tables 1 and 2. Third, with our study being ecological and observational, we need to be wary of the ecological fallacy. The aggregate-level findings may not be applicable to individuals. However, our comparison of patient characteristics was an individually based one. Fourth, although this was a national study the findings may not be applicable to other countries with different health systems.

Finally, we relied on clinicians to provide retrospective data on the patients who had died, which may introduce recall bias. However, most of the questionnaire items concerned objective information (such as gender, age, date of death, method of suicide, living circumstances, in-patient or community patient, 
treatment received, information on last contact) and the majority were completed by frontline clinicians who had seen or treated the patients prior to suicide (around three-quarters of respondents had direct contact with the patient). Some information such as the date of death and method of suicide was also obtained from ONS. NCISH response rates and data completeness are high. ${ }^{17}$

\section{Implications}

We found that the rise in male suicide deaths around the time of the recession reported in previous studies was also reflected in a clinical population. More recently, we found a fall in male patient suicide since 2012, and this was most marked in the group who experienced the largest recession-related rises in suicide (those aged 45-54). An improved economic outlook as well as better clinical services could have also played a role in this reduction. ${ }^{17}$

How might services and clinicians respond to these findings? Mental health service providers should be aware of the potential impact of wider economic factors on their patients who may be among the most vulnerable groups in society. This is particularly pertinent at a time when the UK faces further economic uncertainty as a result of its planned withdrawal from the European Union. Men in midlife and younger men may be most at risk. There has been an increase in the number of people accessing mental health services and it is important that patient safety more generally and suicide prevention in particular remain priorities. ${ }^{28}$ One of our findings was the fall in suicide among patients in 2012-2016 and this was against an increase in the number of people seen by services. This may be an indication of an increased focus on patient safety in services as a result of the National Suicide Prevention Strategy (2012). ${ }^{29}$ In addition, measures to tackle drug and alcohol misuse and greater emphasis on support and interventions for people experiencing economic strain, may help reduce the risk of mental illness and suicide at times of an economic recession. ${ }^{30}$ Specific interventions such as job clubs or group cognitive-behavioural treatment might also be of benefit. ${ }^{31}$

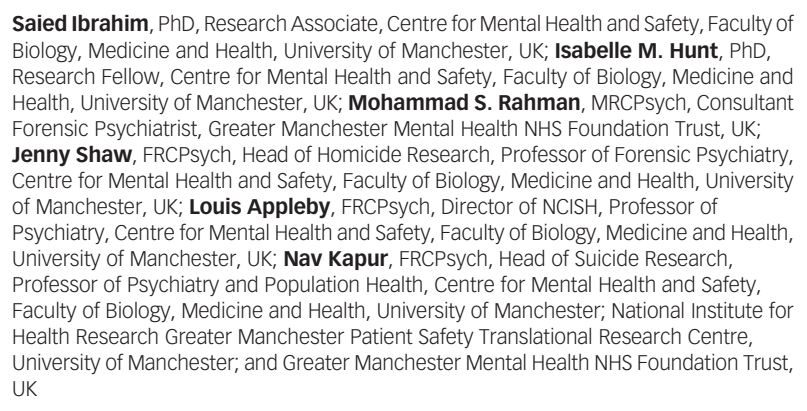

Saied Ibrahim, PhD, Research Associate, Centre for Mental Health and Safety, Faculty of Biology, Medicine and Health, University of Manchester, UK; Isabelle M. Hunt, PhD, Research Fellow, Centre for Mental Health and Safety, Faculty of Biology, Medicine and Health, University of Manchester, UK; Mohammad S. Rahman, MRCPsych, Consultant Forensic Psychiatrist, Greater Manchester Mental Health NHS Foundation Trust, UK; Jenny Shaw, FRCPsych, Head of Homicide Research, Professor of Forensic Psychiatry, Centre for Mental Health and Safety, Faculty of Biology, Medicine and Health, University of Manchester, UK; Louis Appleby, FRCPsych, Director of NCISH, Professor of Psychiatry, Centre for Mental Health and Safety, Faculty of Biology, Medicine and Health, University of Manchester, UK; Nav Kapur, FRCPsych, Head of Suicide Research, Professor of Psychiatry and Population Health, Centre for Mental Health and Safety, Faculty of Biology, Medicine and Health, University of Manchester; National Institute for Health Research Greater Manchester Patient Safety Translational Research Centre, University of Manchester; and Greater Manchester Mental Health NHS Foundation Trust, UK

Correspondence: Saied Ibrahim, Centre for Suicide Prevention, Centre for Mental Health and Safety, University of Manchester, Manchester M13 9PL, UK. Email: saied.a.ibrahim@manchester.ac.uk

First received 5 Oct 2018, final revision 25 Mar 2019, accepted 23 Apr 2019

\section{Supplementary material}

Supplementary material is available online at https://doi.org/10.1192/bjp.2019.119

\section{References}

1 Norström T, Grönqvist $\mathrm{H}$. The Great Recession, unemployment and suicide. J Epidemiol Community Health 2015; 69: 110-6.

2 World Health Organization. The Financial Crisis and Global Health: Report of a High-Level Consultation. WHO, 2009 (http://apps.who.int/iris/bitstream/ 10665/70440/1/WHO_DGO_2009.1_eng.pdf).

3 Reeves A, Basu S, McKee M, Marmot M, Stuckler D. Austere or not? UK coalition government budgets and health inequalities. J R Soc Med 2013; 106: 432-6.

4 Stuckler D, Basu S, Suhrcke M, Coutts A, McKee M. The public health effect of economic crises and alternative policy responses in Europe: an empirical analysis. Lancet 2009; 374: 315-23.

5 Chang SS, Stuckler D, Yip P, Gunnell D. Impact of 2008 global economic crisis on suicide: time trend study in 54 countries. BMJ 2013; 347: f5239.

6 Reeves A, McKee M, Gunnell D, Chang SS, Basu S, Barr B, et al. Economic shocks, resilience, and male suicides in the Great Recession: cross-national analysis of 20 EU countries. Eur J Public Health 2015; 25: 404-9.

7 Webb R, Kapur N. Suicide, unemployment, and the effect of economic recession. Lancet Psychiatry 2015; 2: 196-7.

8 Barr B, Taylor-Robinson D, Scott-Samuel A, McKee M, Stuckler D. Suicides associated with the 2008-10 economic recession in England: time trend analysis. BMJ 2012; 345: e5142.

9 Karanikolos M, Mladovsky P, Cylus J, Thomson S, Basu S, Stuckler D, et al. Financial crisis, austerity, and health in Europe. Lancet 2013; 381: 1323-31.

10 Coope C, Gunnell D, Hollingworth W, Hawton K, Kapur N, Fearn V, et al. Suicide and the 2008 economic recession: who is at most risk? Trends in suicide rates in England and Wales 2001-2011. Soc Sci Med 2014; 117: 76-85.

11 Barr B, Kinderman $P$, Whitehead $M$. Trends in mental health inequalities in England during a period of recession, austerity and welfare reform 2004 to 2013. Soc Sci Med 2015; 147: 324-31.

12 Haw C, Hawton K, Gunnell D, Platt S. Economic recession and suicidal behaviour: possible mechanism and ameliorating factors. Int J Soc Psychiatry 2015; 61: 73-81.

13 McDaid D. Socioeconomic Disadvantage and Suicidal Behaviour During Times of Economic Recession and Recovery. Socioeconomic Disadvantage and Suicide Behaviour, Samaritans, 2017 (http://eprints.Ise.ac. uk/69795/).

14 Evans-Lacko S, Knapp M, McCrone P, Thornicroft G, Mojtabai R. The mental health consequences of the recession: economic hardship and unemployment of people with mental health problems in 27 European countries. PLOS One 2013; 8: e69792.

15 Coope C, Donovan J, Wilson C, Barnes M, Metcalfe C, Hollingworth W, et al. Characteristics of people dying by suicide after job loss, financial difficulties and other economic stressors during a period of recession (2010-2011): a review of coroner's records. J Affect Disord 2015; 183: 98-105.

16 Hawton K. Sex and suicide. Gender differences in suicidal behaviour. Br J Psychiatry 2000; 177: 484-5.

17 Healthcare Quality Improvement Partnership. National Confidential Inquiry into Suicide and Homicide by People with Mental IIIness (NCISH). Annual Report 2017. HQIP, 2017 (https://www.hqip.org.uk/resource/national-confidential-inquiry-into-suicide-and-homicide-annual-report-2017/\#. XNPQ7THsbIU)

18 Office for National Statistics. Estimates of the Population for the UK, England and Wales, Scotland and Northern Ireland. ONS, no date (https://Www.ons.gov. uk/peoplepopulationandcommunity/populationandmigration/populationestimates/datasets/

populationestimatesforukenglandandwalesscotlandandnorthernireland).

$19 \mathrm{Kim} \mathrm{HJ}$, Fay MP, Feuer EJ, Midthune DN. Permutation tests for joinpoint regression with applications to cancer rates. Stat Med 2000; 19: 335-51.

20 Office for National Statistics. The 2008 Recession 10 Years On. ONS, 2018 (https://www.ons.gov.uk/economy/grossdomesticproductgdp/articles/ the2008recession10yearson/2018-04-30).

21 Statacorp. Stata Statistical Software: Release 13.1. Stata Statistical Software. StataCorp LP, 2015

22 Hawton K, Bergen H, Geulayov G, Waters K, Ness J, Cooper J, et al. Impact of the recent recession on self-harm: Iongitudinal ecological and patient-level investigation from the Multicentre Study of Self-harm in England. J Affect Disord 2016; 191: 131-9.
The study was part of the National Confidential Inquiry into Suicide and Safety in Mental Health (NCISH) and we thank the other members of the research team: Pauline Turnbull, Cathryn Rodway, Alison Baird, Su-Gwan Tham, Myrsini Gianatsi, Jane Graney, Lana Bojanic, Nicola the administrative staff in NHS Trusts who helped with the NCISH processes and the clinicians and nurses who completed the questionnaires. 
23 Eliason M, Storrie D. Job loss is bad for your health - Swedish evidence on cause-specific hospitalization following involuntary job loss. Soc Sci Med 2009; 68: $1396-406$.

24 Hunt IM, Rahman MS, While D, Windfuhr K, Shaw J, Appleby L, et al. Safety of patients under the care of crisis resolution home treatment services in England: a retrospective analysis of suicide trends from 2003 to 2011. Lancet Psychiatry 2014; 1: 135-41.

25 Saurina C, Bragulat B, Saez M, López-Casasnovas G. A conditional model for estimating the increase in suicides associated with the 2008-2010 economic recession in England. J Epidemiol Community Health 2013; 67: 779-87.

26 Department for Work and Pensions. Employment and Support Allowance: Outcomes of Work Capability Assessments. DWP, 2013 (https://assets.publishing.service.gov.uk/government/uploads/system/uploads/attachment data/file/200001/esa wca summary apr13.pdf).

27 Nagelhout GE, Hummet K, de Goeij MCM, de Vries H, Kaner E, Lemmens P. How economic recession and unemployment affect illegal drug use: a systematic realist literature review. In J Drug Policy 2017; 44: 69-83.
28 National Health Service Digital. Mental Health Service Data Set (MHSDS) Mental Health Bulletin, Annual Report - 2014-15. National Health Service Digital, no date (http://content.digital.nhs.uk/mhldsreports)

29 Department of Health and Social Care. Preventing Suicide in England - A CrossGovernment Outcomes Strategy to Save Lives. Department of Health and Social Care, 2012 (www.gov.uk/government/publications/suicide-preventionstrategy-for-england).

30 Moore TH, Kapur N, Hawton K, Richards A, Metcalfe C, Gunnell D. Interventions to reduce the impact of unemployment and economic hardship on mental health in the general population: systematic review. Psychol Med 2017; 47 1062-84.

31 Robinson J, Hetrick SE, Martin C. Preventing suicide in young people: systematic review. Aust N Z J Psychiatry 2011; 45: 3-26.

\section{Psychiatry in history}

\section{Benjamin of Tudela, the Caliph of Baghdad and the first mental hospital}

\section{Greg Wilkinson}

Rabbi Benjamin's Travels (c1159-1173) ${ }^{1}$ from Zaragoza through Europe, Asia and the Arabian peninsula is an unsurpassed source on the contemporaneous Mediterranean and Arabic world. Whether by metaphor, trope or diplomacy, it provides a unique description of the care of 'the insane' in Baghdad - great city and royal residence of Caliph Emir al Muminin al Abbasi - where, much earlier, in 705, the first mental hospital was reputedly built.

'He built, on the other side of the river, on the banks of an arm of the Euphrates which there borders the city, a hospital consisting of blocks of houses and hospices for the sick poor who come to be healed. Here there are about sixty physicians' stores which are provided from the Caliph's house with drugs and whatever else may be required. Every sick man who comes is maintained at the Caliph's expense and is medically treated. Here is a building which is called Dar-al-Maristan, where they keep charge of the demented people who have become insane in the towns through the great heat in the summer, and they chain each of them in iron chains until their reason becomes restored to them in the wintertime.

Whilst they abide there, they are provided with food from the house of the Caliph, and when their reason is restored they are dismissed and each one of them goes to his house and his home. Money is given to those that have stayed in the hospices on their return to their homes. Every month the officers of the Caliph inquire and investigate whether they have regained their reason, in which case they are discharged. All this the Caliph does out of charity to those that come to the city of Bagdad, whether they be sick or insane. The Caliph is a righteous man, and all his actions are for good.'

The Caliph did not restrict chains to patients:

'Each of his brothers and the members of his family has an abode in his palace, but they are all fettered in chains of iron, and guards are placed over each of their houses so that they may not rise against the great Caliph. For once it happened to a predecessor that his brothers rose up against him and proclaimed one of themselves as Caliph; then it was decreed that all the members of his family should be bound, that they might not rise up against the ruling Caliph. Each one of them resides in his palace in great splendour, and they own villages and towns, and their stewards bring them the tribute thereof, and they eat and drink and rejoice all the days of their life.'

O tempora, O mores. The Caliph was 'a benevolent man':

'kind unto Israel, and many belonging to the people of Israel are his attendants; he knows all languages, and is well versed in the law of Israel. He reads and writes the holy language [Hebrew]'.

\section{Reference}

1 Adler MN. The Intinerary of Benjamin of Tudela. Oxford University Press, 1907. 